\title{
Análisis comparativo de la movilidad social educativa intergeneracional en España y México ${ }^{1}$
}

\section{Comparative analysis of intergenerational educational mobility in Spain and Mexico}

DOI: https://doi.org/10.32870/dse.v0i12.262

\section{César Augusto Ricardi Morgavi*}

\begin{abstract}
Resumen: En el presente artículo se desarrolla el análisis en perspectiva comparada de la movilidad educativa intergeneracional absoluta y relativa de las sociedades española y mexicana. Se analiza la reproducción, ascenso y descenso educativo a partir de matrices de transición de la movilidad educativa con y sin la introducción del factor temporal de las cohortes de nacimiento. Se estudian los niveles de adscripción educativa por herencia de posiciones y los grados de permeabilidad educacional en España y México, al tiempo que se desarrolla un análisis de la movilidad educativa estructural y de reemplazo, y de la movilidad educativa relativa a partir de la evaluación comparada de modelos log-lineales aplicados al estudio de la movilidad en un contexto de expansión educativa y posterior crisis económica y reducción del gasto público en educación. Palabras clave: movilidad educativa, reproducción, cohortes, España, México.
\end{abstract}

\begin{abstract}
This article presents a compared perspective analysis of the absolute and relative intergenerational educational mobility in the Mexican and Spanish societies. Educational reproduction and upward and downward mobility are analyzed working from transition matrixes of educational mobility, with and without the integration of the temporal factor of the birth cohorts. The levels of educational ascription through inherited positions, and the degrees of educational permeability in both countries are analyzed; relative, structural and replacement educational mobility is also studied through the compared evaluation of loglinear models applied to the study of educational mobility in a context of educational expansion, subsequent economic crisis and reduction of public expense in education. Keywords: educational mobility, reproduction, birth cohorts, Spain, Mexico.
\end{abstract}

\section{Introducción}

El artículo que aquí se presenta aborda el tema de la movilidad educativa intergeneracional en España y México a partir de una aproximación comparativa que integra el análisis de la movilidad educativa absoluta y relativa basado en matrices de transición y modelos log-lineales. La movilidad educativa se refiere en este estudio a la movilidad existente entre generaciones, esto es, la movilidad existente entre los orígenes (O) (nivel educativo del padre) ${ }^{2}$ y los destinos educativos (D) (nivel educativo de los/as hijos/as) que tiene lugar en las sociedades puestas bajo estudio. Mientras la movilidad educativa intergeneracional absoluta es el resultado de cruzar el origen educativo (O) con la posición educativa de destino (D), y permite describir y analizar la movilidad entre dos momentos

${ }^{1}$ El presente artículo es el resultado de una investigación en curso desarrollada por quien escribe sobre movilidad social ocupacional y educativa en perspectiva comparada internacional para una selección de países de Europa y América Latina.

${ }^{2}$ Este artículo considera el nivel educativo del padre varón como el nivel educativo de origen (O) de los/as hijos/as.

* Candidato a Doctor en Sociología (Universidad de Barcelona, España) y Ciencias Sociales (Universidad de Guadalajara, México). Correo electrónico: sociologicalthinktankblog@gmail.com 
diferentes, la movilidad educativa intergeneracional relativa, o fluidez educativa, permite conocer el nivel de apertura-cierre de la estratificación educativa en una sociedad determinada y para un período de tiempo dado, mediante el estudio del grado de independencia entre orígenes y destinos educativos en la tabla de movilidad. En términos generales, por movilidad educativa se entenderá el salto jerárquico ascendente o descendente de los individuos desde unas categorías educativas hacia otras en la estructura de estratificación educacional. Su estudio, que implica el conocimiento del ascenso, inmovilidad (herencia de posiciones), y descenso en los niveles educativos entre padres e hijos/as, requiere la utilización de la Clasificación Internacional Normalizada de Educación CINE (ISCED, de sus siglas en inglés International Standard Classification of Education). ${ }^{3}$

El análisis de la movilidad educativa intergeneracional integra el estudio de la movilidad educativa estructural, que refiere a la movilidad educativa entre padres e hijos/as debida a los cambios que han tenido lugar en la estructura educativa y/o demográfica, y el análisis de la movilidad de reemplazo, que corresponde al resto de la movilidad educativa observada en la tabla y aísla los efectos de los cambios estructurales. El análisis de la movilidad educativa relativa en términos del grado y naturaleza de la fluidez educativa, acompasado del análisis de la movilidad educativa absoluta, resulta pertinente al poner luz sobre el porcentaje total de individuos cuya categoría de origen y destino son diferentes, es decir, sobre el conocimiento de la movilidad educativa total, así como la distribución de los diferentes orígenes educativos de los individuos situados en una misma categoría de destino (movilidad de entrada), y el comportamiento en la evolución intercohortes de los patrones de movilidad.

El análisis comparativo de los niveles de movilidad educativa en las sociedades como la mexicana y la española revisten especial interés en la medida en que se constata que un elevado margen de la desigualdad existente en Latinoamérica se explica tanto por los "retornos diferenciales a distintos niveles de educación, en particular los elevados retornos a la educación superior" (Beyer y Le Foulon 2002, y Duryea y Pages 2002, citados en Torche, 2007: 6) los que "podrían haberse incrementado en las últimas dos décadas en el contexto de liberalización económica experimentada [en México]"4 (Cragg y Epelbaum, 1996, y Robbins, 1995, en Torche, 2007: 6), como porque la educación "cumple dos roles contrapuestos en la transmisión de las ventajas o desventajas sociales a través del tiempo [al constituirse en] el principal mecanismo mediador de las ventajas de origen social [y en] la principal fuente de bienestar independiente del origen social, creando oportunidades de movilidad" (Torche, 2007: 6). Con ello se quiere indicar que padres con mayores

\footnotetext{
${ }^{3}$ Los niveles de la clasificación ISCED que se emplean en el análisis son: nivel por debajo del nivel inferior del secundario (ISCED 0-1), nivel inferior del secundario completo (ISCED-2), nivel superior del secundario completo (ISCED 3), nivel de educación post-secundaria no-terciaria completa (ISCED 4), y nivel de educación terciaria completa (ISCED 5-6).

${ }^{4}$ Para una profundización de la relación de determinación entre los elevados retornos económicos hacia niveles educativos universitarios y el bienestar económico en sociedades contemporáneas a nivel mundial y en América Latina, véase Birdsall y Lodoño (1997), Cragg y Epelbaum (1996), y Psacharopoulos y Patrinos (2002).
} 
Análisis comparativo de la movilidad social educativa intergeneracional en España y México

recursos - entre los que se cuenta el capital educativo- invierten más en educación para sus hijos/ as, ampliando sus ventajas comparativas de partida y de logro del bienestar económico en la vida adulta. Si se presta atención al trabajo de Torche (s.a.) surge el interés por formular la interrogante de por qué reviste relevancia profundizar en el estudio de la educación y la formación desde los análisis de la movilidad educativa.

Puede responderse que en primer lugar, por un criterio de "eficiencia", en segundo, por uno de "razones normativas", y en tercer lugar, por uno de "integración social". Por eficiencia, porque una sociedad educacionalmente inmóvil que no proporciona chances de movilidad social para quienes provienen de orígenes sociales de bajos recursos socioeconómicos, no logrará mejorar el uso de sus recursos y talentos humanos existentes anclando a sus miembros en un equilibrio por debajo del óptimo de su capacidad (Torche, s.a.). Por razones normativas, porque la relevancia de estudiar la movilidad educativa reside en conocer mejor la fuerza que tienen los orígenes sociales y educativos en el éxito educativo y bienestar futuro de los individuos, lo que debe considerarse una cuestión de justicia social (Torche, s.a.). Y por integración social, en el sentido de que una sociedad educacionalmente inmóvil, caracterizada por una rigidez de su estructura de movilidad educativa, erosiona la legitimidad e integración social así como la cohesión, el tejido social y su regeneración.

\section{Lo que interesa conocer (problematización de la movilidad educativa)}

El artículo ofrece conocimiento nuevo sobre los modos en que se distribuyen las oportunidades de movilidad educativa entre generaciones en un punto del tiempo determinado como a través del mismo (análisis de cohortes). Se identifican pautas comunes y diferenciadas de movilidad educativa intergeneracional mediante el análisis de muestras probabilísticas, que en el caso de España es el resultado de un muestreo probabilístico estratificado polietápico, con un error muestral de 5\% y $\mathrm{n}=1244$, y en el mexicano de un muestreo por conglomerados y selección por etapas, con un error absoluto esperado máximo de \pm tres puntos porcentuales y $\mathrm{n}=6531$. Se explotan dos bases de datos, la Encuesta Social Europea (ESE) (ESS, de sus siglas en inglés European Social Survey) del año 2010 para el caso español, y la Encuesta de Movilidad Social EMOVI del 2011 para el mexicano.

Las interrogantes que impulsan la investigación son, ¿de qué se está hablando cuando en el ámbito de la sociología que estudia la movilidad social se habla de movilidad educativa intergeneracional en España y México? Por consiguiente, ¿qué se puede aportar de nuevo a su conocimiento en estas dos sociedades a partir del examen comparativo de tablas de movilidad y modelos explicativos de la movilidad educativa relativa? ¿Es posible afirmar la existencia de una persistencia a través de las generaciones de un patrón de movilidad educativa en el caso español y en el mexicano? ¿El patrón informa de una movilidad variante o invariante a través del tiempo? ¿Se aproximan o se distancian, y de qué modo, la sociedad española y la mexicana en términos de igualdad de oportunidades para la movilidad educativa? 


\section{Estado de la cuestión (debates)}

El análisis desarrollado en este artículo se encuentra motivado por el hecho de que investigar la movilidad educativa intergeneracional absoluta y relativa en el contexto de la sociedad española y en el de la sociedad mexicana, contribuye a llenar un vacío de conocimiento vigente. La autora Sánchez (2004: 3) afirma que sigue siendo reducido el número de autores que se han interesado por el estudio de la movilidad educativa intergeneracional relativa en España cuando se compara con el número de autores y la atención que se ha dedicado al estudio de la movilidad social ocupacional y de ingresos. Entiende la autora que aún existe un déficit en la producción de conocimiento acumulado sobre movilidad educativa en España en términos de investigación longitudinal y cuantitativa (Sánchez, 2004).

Cuando Sánchez identifica la existencia de un vacío en la producción de conocimiento sobre movilidad educativa en España, está haciendo referencia al carácter tangencial que ha tenido el estudio de este tipo de movilidad social en los estudios más amplios de movilidad social ocupacional para la sociedad española. Asimismo, el estudio de la movilidad social intergeneracional relativa en España se inspira en enfoques de desigualdad de ingresos, renta o estatus ocupacional, más que de distribución de oportunidades educativas para la movilidad. Al margen de lo expuesto, pueden identificarse contribuciones sustantivas en el campo de estudio de la movilidad educativa para el caso español, entre las que previo a los años noventa han de contarse los trabajos de Sánchez López (1961), Lipset y Bendix (1963), Linz y Amando De Miguel (1963, 1966a, 1966b), Amando De Miguel (1965, 1966), Orizo (1965), Pinilla de las Heras (1965, 1979), Blanc (1966), los informes Foessa (1970, 1975, 1983), y Carabaña (1983) (citados en Ricardi, 2012).

Hacia la década de los años noventa el tema de la movilidad educativa en la sociedad española cobra centralidad y se genera una serie de producciones relevantes que la integran al análisis, aunque continúa haciéndose de forma tangencial sin que conforme un eje temático articulador y central del análisis. Entre las aportaciones se destacan las de Cachón Rodríguez (1989), Amando De Miguel (1992, 1994, 1995), Jesús De Miguel (1998), Carabaña (1999), Echeverría Zabalza (1999), Cantó (2000), el quinto Informe Foessa (2000), Prieto-Rodríguez y Salas (2002), AyalaSastre (2002) (citados en Ricardi, 2012).

Más recientemente, estudios como los de Calero (2006) y Calero et al. $(2007,2008)$ han incursionado en el análisis de la movilidad educativa en España con especial énfasis en el análisis de la movilidad educativa relativa mediante la aplicación de medidas de asociación estadística y de modelos log-lineales para dos y más variables. A éstos se suma la investigación desarrollada por Martínez Celorrio y Marín Saldo (2010), en la que se analiza la movilidad educativa intergeneracional en términos de desigualdad relativa de oportunidades para la sociedad catalana, la que es comparada con la española y una selección de otras sociedades europeas. De un modo algo más colateral, Mediavilla y Calero (2010), desde un enfoque de la reproducción de las desigualdades educativas, dedican su atención al estudio comparativo de la movilidad educativa en seis países 
Análisis comparativo de la movilidad social educativa intergeneracional en España y México

latinoamericanos (Argentina, Brasil, Chile, México, Perú y Venezuela), introduciendo observaciones puntuales sobre el comportamiento de las pautas de movilidad entre estos países y los países desarrollados. No obstante, su estudio no profundiza en la comparación entre los casos latinoamericanos y los países de economía avanzada —en su estudio, España y Estados Unidos-, con lo cual no se logra delinear con claridad las diferencias en los patrones de movilidad educativa entre uno y otros.

En México se han llevado a cabo iniciativas de éxito como la desarrollada por el Centro de Estudios Espinosa Yglesias (CEEY). El estudio de la movilidad social en el caso mexicano ha sido ante todo el de las dinámicas que imperan en el mercado de trabajo, como son los análisis desarrollados por Escobar $(1993,1995)$ y en Escobar y Cortes (2002). Éstos se inscriben dentro de los estudios de movilidad de nivel analítico sistémico más que en los de tipo institucionales o estructurales, lo que derivó en que se partiera de un concepto amplio sobre el mercado laboral visto como factor que condiciona y determina fuertemente la estructura social. Este modo de aproximarse al fenómeno estaba influido por una coyuntura mexicana caracterizada por la reestructuración económica neoliberal de los años ochenta e intensificada en los noventa (Boado, 2008).

El abordaje empírico de la movilidad social en México estuvo influido en algunos casos - relevantes para este estudio - por autores provenientes de la teoría de la similaridad entre naciones. Es el caso del primer trabajo de Escobar (1995) en el que se analiza la movilidad como reproducción social a partir del uso de matrices de ventajas relativas (razones de probabilidades, u odds ratio) y tasas de disparidad. En este caso Escobar hace suyo el análisis de movilidad intergeneracional e intrageneracional que desarrolla Goldthorpe en su estudio de 1980, ahora aplicado a la movilidad social ocupacional de trabajadores de diferentes estratos que residen en la metrópolis de Guadalajara en México. Es posible objetar en el estudio de Escobar el que haya dejado fuera del análisis la movilidad educativa intergeneracional y el examen más profundo del régimen de movilidad social ocupacional. Sin embargo, es gracias a su estudio que se accede al conocimiento del efecto que generan los cambios macroeconómicos sobre los logros ocupacionales de los individuos, así como el modo en que las diferencias en la movilidad intrageneracional entre estratos ocupacionales se encuentran en función de los ciclos económicos de crecimiento y crisis. La dependencia de las diferencias frente a los ciclos económicos se hace más intensa en México cuando se introducen al modelo explicativo variables transversales como la de género (Boado, 2008).

De un modo análogo a lo que se ha descrito para el caso español, la producción académica de estudios de movilidad social en México se ha enfocado en la generación de conocimiento relativo a la movilidad social ocupacional intergeneracional e intrageneracional. Más reciente en el tiempo, se han llevado a cabo contribuciones sustantivas en el campo del estudio de la movilidad educativa, entre los que cabe destacar el desarrollado por Torche (2007), en el que se lleva a cabo un análisis comparativo de la movilidad social en México y Chile integrando la movilidad de bienestar económico, la movilidad subjetiva (percibida), y la movilidad educativa, así como con un análisis de 
la homogamia educacional en ambos países. El análisis tiene por punto de partida la influencia que ejerce la desigualdad sobre la cohesión social de las sociedades, mediante el condicionamiento que sobre las oportunidades educacionales y de bienestar económico tienen los recursos que dispone la generación previa, o como los denomina la autora, los "accidentes de la cuna" (Torche, 2007: 2).

El análisis de Torche (2007) proporciona un hallazgo basado en la constatación de la existencia de una pauta de movilidad educativa compartida en México y Chile, que se caracteriza por férreas barreras a la movilidad educativa ascendente hacia los niveles de educación superior, que puede ser interpretado como una alta reproducción intergeneracional de posiciones en la cumbre de la estructura educativa. Los análisis comparativos que integran países de economías avanzadas tienden a concluir que este patrón es un rasgo distintivo de las sociedades de América Latina, por lo que México y Chile constituyen casos interesantes para desarrollar análisis comparado internacional de movilidad social.

En el caso de México, señala la autora, los avances en materia de análisis de la movilidad educativa resultan ser más modestos que los observados para el caso chileno, lo que se explica en buena medida por la escases de bases de datos (databases) específicas sobre movilidad social con representación a nivel nacional. Lo que se sabe hasta ahora proviene de análisis de movilidad intergeneracional a partir de muestras urbanas, las que sugieren que en México -al igual que en Chile - se registra un incremento en la fuerza con que los recursos de origen inciden en el logro educativo de las personas durante los años ochenta, siendo necesario contar con información que permita el análisis para años recientes (Torche, 2007: 5).

El análisis de la movilidad educativa en México que desarrolla Torche comprende un análisis de la movilidad educativa absoluta y otro de movilidad educativa relativa. De ellos surge que la elevada desigualdad que caracteriza a la región latinoamericana se explica por los diferenciales existentes en los retornos de capital económico, los que se encuentran a su vez en función de los niveles educativos alcanzados y, muy en concreto, por el acceso y finalización de los niveles de educación superior (universitaria y post-secundaria no-universitaria). Asimismo, se concluye que la educación es un factor que media entre las desventajas de origen y lo logros económicos y educativos del individuo en su vida adulta, siendo que cuanto más recursos tienen los progenitores, más invierten en la educación de su progenie, siendo así mayores las ventajas resultantes de bienestar económico de sus hijos/as. Adicionalmente, con base en el análisis desarrollado es posible afirmar que para el caso de México, la educación en tanto capital conforma una fuente de bienestar relativamente independiente de los recursos del origen social.

En un análisis que complementa al recién descrito, Torche (s.a.) retoma el examen de la movilidad educativa intergeneracional en la sociedad mexicana para profundizar en el estudio del cambio del régimen de movilidad a través del tiempo, mediante la incorporación de las cohortes de nacimiento. Si bien en su análisis comparativo de la movilidad educativa entre México y Chile (Torche, 2007) se estudiaba el cambio temporal a partir de la variable de las cohortes de nacimiento, éste era sólo con base en tres momentos (cohortes). Al ampliarse a cuatro momentos (cohortes), 
el análisis de Torche (s.a.) aumenta su precisión en la interpretación de los resultados obtenidos con la aplicación de modelos log-lineales al análisis de la movilidad, particularmente, en la aplicación del modelo "de cruce" - único que aplica el análisis de su artículo del 2007-complementado con la aplicación de los modelos de fluidez constante y diferencia uniforme (unidiff).

\section{La movilidad educativa absoluta en España}

Ascenso, descenso, y reproducción educativa en España

El siguiente análisis revisa los niveles de ascenso, descenso y reproducción educativa entre orígenes y destinos educativos de los/as españoles de entre 25 y 65 años de edad. La proporción de ascenso educativo existente en una sociedad se obtiene sumando los porcentajes observados en la tabla de movilidad educativa que se encuentran por debajo de la diagonal. La proporción del descenso educativo se obtiene mediante la sumatoria de los porcentajes observados en la tabla de movilidad educativa que se encuentran por encima de la diagonal. La proporción de la reproducción o herencia educativa se obtiene de la sumatoria de los porcentajes observados en la diagonal de la tabla de movilidad educativa (sombreada en gris claro en la tabla 1). Lo primero que se puede apreciar en el caso de la sociedad española es que el ascenso educativo, esto es, la superación del nivel educativo del padre por parte de los/as hijos/as, es de $60.3 \%$ (tabla 1). El descenso educativo, que supone la situación inversa, es decir, la no superación del nivel educativo del padre por parte de los hijos/as, es igual a 4.6\% (tabla 1). Mientras que la reproducción educativa, es decir, la conservación por parte de los/as hijos/as del nivel educativo alcanzado por sus padres, es igual a $35.1 \%$ (tabla 1). Una primera constatación con base en los porcentajes observados permite afirmar que se trata de una sociedad que, para el tramo etario de la población estudiada ( 25 a 65 años), muestra una estructura de movilidad educativa bastante "fluida" al registrar una tasa de movilidad educativa total igual a $64.9 \%$ (ascenso más descenso) conformada en su mayor parte por movimientos de tipo ascendente.

Tabla 1. Relación entre nivel educativo del padre y de los y las hijos/as (frecuencias absolutas y relativas)

\begin{tabular}{|c|c|c|c|c|c|c|c|c|}
\hline \multirow{2}{*}{\multicolumn{3}{|c|}{ España }} & \multicolumn{5}{|c|}{ Nivel educativo del hijo/a (destino) } & \multirow[b]{2}{*}{ Total } \\
\hline & & & ISCED 5-6 & ISCED 4 & ISCED 3 & ISCED 2 & ISCED 0-1 & \\
\hline \multirow{10}{*}{ 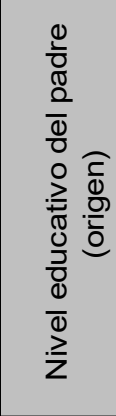 } & ISCED 5-6 & Cuenta & 106 & 11 & 15 & 6 & 0 & 138 \\
\hline & & $\%$ del total & 8.5 & 0.9 & 1.2 & 0.5 & 0 & 11.1 \\
\hline & ISCED 4 & Cuenta & 16 & 3 & 3 & 3 & 1 & 26 \\
\hline & & $\%$ del total & 1.3 & 0.2 & 0.2 & 0.2 & 0.1 & 2.1 \\
\hline & ISCED 3 & Cuenta & 27 & 8 & 8 & 5 & 3 & 51 \\
\hline & & $\%$ del total & 2.2 & 0.6 & 0.6 & 0.4 & 0.2 & 4.1 \\
\hline & ISCED 2 & Cuenta & 59 & 19 & 29 & 39 & 10 & 156 \\
\hline & & $\%$ del total & 4.7 & 1.5 & 2.3 & 3.1 & 0.8 & 12.5 \\
\hline & ISCED 0-1 & Cuenta & 153 & 71 & 112 & 256 & 281 & 873 \\
\hline & & $\%$ del total & 12.3 & 5.7 & 9.0 & 20.6 & 22.6 & 70.2 \\
\hline \multirow[t]{2}{*}{ Total } & & Cuenta & 361 & 112 & 167 & 309 & 295 & 1244 \\
\hline & & $\%$ del total & 29.0 & 9.0 & 13.4 & 24.8 & 23.7 & 100 \\
\hline
\end{tabular}

Fuente: Elaboración propia sobre la base de la European Social Survey, 2010. 
En un segundo orden de observaciones se constata que el mayor porcentaje de reproducción educativa (22.6\%) tiene lugar en el nivel educativo de quienes no han logrado superar con éxito el primer ciclo de la educación secundaria, es decir, en aquellos que sólo han alcanzado un nivel equivalente a educación primaria completa y que en la clasificación CINE (ISCED) se corresponde con la categoría CINE 0-1 (ISCED 0-1). La reproducción educativa en ISCED 0-1 representa 64.4\% del volumen total absoluto de reproducción, y la que tiene lugar entre padres e hijos/as que han superado con éxito la educación terciaria ISCED 5-6 (8.5\%), representa 24.2\% del volumen total absoluto de reproducción. La reproducción educativa en la sociedad española tiende a concentrarse en los niveles educativos ubicados en los extremos de la estructura educativa, conformando una suerte de circuitos "cerrados" de herencia de posiciones educativas en los niveles "extremos", siendo más fuerte en el nivel inferior (ISCED 0-1) que en el superior (ISCED 5-6) (tabla 1).

En un tercer orden de observaciones, se constata que del total de ascenso educativo que experimentan los/as hijos/as de padres españoles (60.3\%), son los que provienen de padres con nivel educativo ISCED 0-1 los que tienen mayor movilidad ascendente (47.6\%) equivalente a $79 \%$ del volumen total absoluto del ascenso educativo (tabla 1). Destaca el hallazgo de que del total de ascenso educativo registrado por los hijos/as de padres de nivel educativo ISCED 0-1 sea hacia la posición contigua del nivel inferior del secundario completo (ISCED 2) que se experimenta la mayor proporción de movilidad ascendente (20.6\%) equivalente al $43.3 \%$ del volumen total absoluto de ascenso desde el origen ISCED 0-1. Le sigue el ascenso que tiene lugar hacia el nivel más alto de educación terciaria completa (ISCED 5-6) (12.3\%) equivalente al 25.8\% del volumen total absoluto de ascenso desde un origen ISCED 0-1. Cabe destacar que existe una elevada proporción de ascenso experimentado por los hijos/as de padres con nivel educativo por debajo del nivel inferior del secundario (ISCED 0-1) que se cumple hacia las dos categorías contiguas que se corresponden con los niveles inferior del secundario completo (ISCED 2) y superior del secundario completo (ISCED 3). Tras sumarlos comprenden $29.6 \%$ del ascenso educativo, equivalente a $62.1 \%$ del volumen total absoluto de ascenso desde el origen ISCED 0-1 (tabla 1).

Con relación al descenso, se observa que son los hijos/as de padres con nivel educativo ISCED 5-6 los que experimentan mayor movilidad descendente (2.6\%) equivalente a 56.5\% del volumen absoluto total de descenso desde el nivel ISCED 5-6 (tabla 1). Resulta relevante referirse al hallazgo de que la mayor proporción del volumen total absoluto de descenso registrado por los hijos/as de padres con nivel educativo ISCED 5-6 tiene lugar hacia las dos posiciones educativas contiguas más bajas de educación de nivel superior del secundario completo (ISCED 3) (1.2\%, equivalente a $46.1 \%$ del volumen absoluto total de descenso desde el origen ISCED 5-6) y de nivel educativo de educación post-secundaria no terciaria completa (ISCED 4) $(0.9 \%$, equivalente a $34.6 \%$ del volumen absoluto total de descenso desde el origen ISCED 5-6) (tabla 1). Nótese que el descenso experimentado por los hijos/as de padres con nivel educativo ISCED 5-6 hacia una posición educativa ubicada en el extremo opuesto e inferior de la estructura educativa (ISCED 0-1) es inexistente (tabla 1). 
Adicionalmente, cuando se examinan los flujos de entrada (inflows) de la movilidad educativa, esto es, el porcentaje de hijos/as que con un mismo destino proceden de diferentes orígenes educativos, se constata que la probabilidad de los/as primeros/as de alcanzar un nivel educativo superior completo (ISCED 5-6) se encuentra influenciada por el nivel educativo logrado por el padre, sin evidenciarse una relación positiva entre una y otro. En contraste, el análisis de los flujos de entrada muestra que la probabilidad de los/as hijos/as de superar los dos niveles educativos más bajos de la estructura educativa (ISCED 0-1 e ISCED 2) se halla en una relación positiva con el nivel educativo del padre; a mayor nivel educativo alcanzado por el padre, mayor es la probabilidad de que los/as hijos/as superen los dos niveles educativos más bajos (gráfico I).

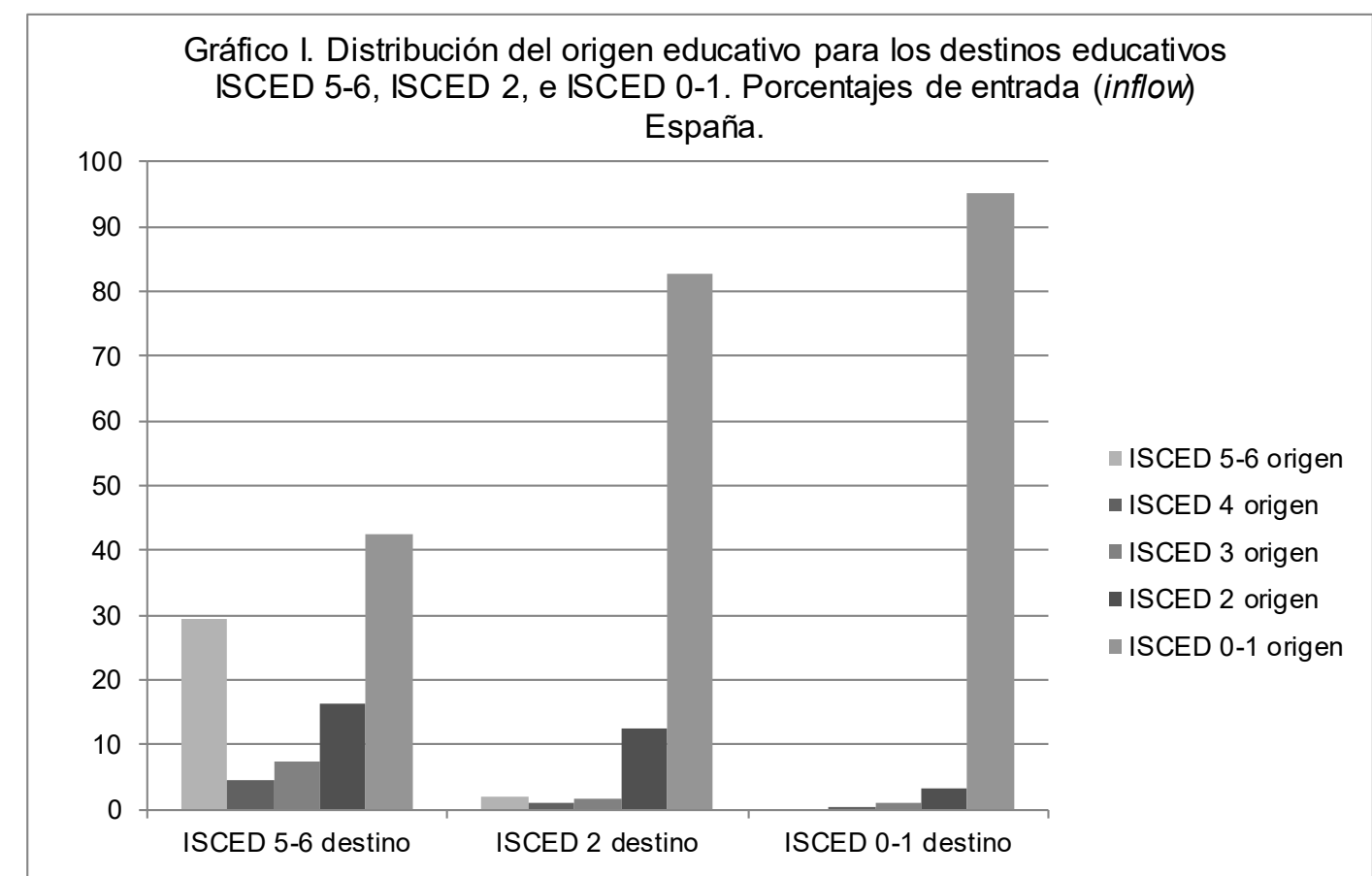

Fuente: Elaboración propia sobre la base de la European Social Survey, 2010.

Evolución intercohortes de ascenso, descenso, y reproducción educativa en España El análisis del ascenso, descenso, y reproducción educativa se hacen más precisos con la introducción de la variable temporal de las cohortes de nacimiento. Para el caso de la sociedad española, se definen tres cohortes de nacimiento. Una cohorte antigua que comprende a quienes han nacido entre los años 1935 y 1950, y que al año $2010^{5}$ tienen entre 60 y 75 años de edad. Una cohorte

${ }^{5}$ Año en que culmina el relevamiento de la información de la encuesta empleada para el análisis de la movilidad social educativa en España. 
intermedia que comprende a quienes han nacido entre 1951 y 1975, y que al año 2010 tienen entre 59 y 35 años de edad, y una cohorte joven que comprende a quienes han nacido entre 1976 y 1986 , y que al año 2010 tienen entre 34 y 24 años de edad.

El análisis de la reproducción y movilidad educativa en la cohorte de nacimiento más antigua (1935-1950) registra una reproducción (72.6\%) superior al ascenso (24.4\%), que es el más bajo de la evolución intercohortes, así como respecto al descenso (3\%), que también es el más bajo de la evolución intercohortes (tabla 2). Puesta en comparación con las dos cohortes más jóvenes, la cohorte antigua presenta la más alta reproducción educativa, que evidencia una fuerte influencia de los orígenes sobre los destinos educativos en términos de posiciones educativas heredadas. En consecuencia, la cohorte antigua exhibe la más baja permeabilidad educativa en la comparación intercohortes, representada por una tasa de movilidad educativa total de $27.4 \%$.

Tabla 2. Dimensiones movildiad social educativa absoluta

\begin{tabular}{|l|r|r|r|}
\hline España & $1935-1950$ & $1951-1975$ & $1976-1986$ \\
\hline Reproducción & $72.6 \%$ & $35.6 \%$ & $27.2 \%$ \\
Ascendente & $24.4 \%$ & $61.0 \%$ & $65.9 \%$ \\
Descendente & $3.0 \%$ & $3.4 \%$ & $6.9 \%$ \\
& $100.0 \%$ & $100.0 \%$ & $100.0 \%$ \\
\hline
\end{tabular}

Fuente: Elaboración propia sobre la base de la ESS, 2010.

En la cohorte intermedia (1951-1975), y respecto a la cohorte más antigua, la reproducción educativa (35.6\%) registra una disminución de 37 puntos porcentuales, un ascenso (61\%) que se incrementa en 36.6 puntos porcentuales, y un descenso educativo que experimenta un leve aumento al pasar de 3\% a 3.4\%. La proporción en que disminuye la reproducción educativa de la cohorte más antigua a la cohorte intermedia, impacta con mayor fuerza sobre el volumen de variación del ascenso que del descenso educativo. La adscripción educativa -influencia de los orígenes sobre los destinos educativos en términos de posiciones educativas heredadas - se reduce sensiblemente en la cohorte intermedia respecto a la antigua, suponiendo un aumento de la permeabilidad educativa expresado por una tasa de movilidad educativa total que pasa de $27.4 \%$ a $64.4 \%$ (tabla 2).

En la cohorte joven (1976-1986), y respecto a la cohorte intermedia, la reproducción disminuye 8.4 puntos porcentuales, cerrando una pauta decreciente de reproducción educativa intercohortes $(72.6 \%, 35.6 \%$, y $27.2 \%$, respectivamente). El ascenso educativo en la cohorte joven respecto a la intermedia aumenta 4.9 puntos porcentuales, definiéndose una pauta incremental de ascenso en la evolución intercohortes $(24.4 \%, 61 \%$ y $65.9 \%$, respectivamente). El descenso educativo registra un aumento de 3.5 puntos porcentuales en la cohorte joven respecto a la intermedia, cerrando una pauta de tenues incrementos en la evolución intercohortes $(3 \%, 3.4 \%$ y $6.9 \%$, respectivamente). En la cohorte más joven se debilita la adscripción educativa por herencia de posicio- 
Análisis comparativo de la movilidad social educativa intergeneracional en España y México

nes, siendo la más baja de las registradas en la comparativa intercohortes (27.2\%), al tiempo que aumenta la permeabilidad educativa que supone la tasa de movilidad educativa total más alta entre las cohortes $(27.4 \%, 64.4 \%$ y $72.8 \%$, respectivamente) (tabla 2$)$.

\section{Movilidad educativa estructural y de reemplazo en España}

La movilidad educativa intergeneracional absoluta se divide en dos partes, movilidad estructural y movilidad de reemplazo, también llamada esta última movilidad individual o circulatoria. La movilidad estructural se define como la movilidad mínima que se requiere para compensar las diferencias entre los marginales de origen y los de destino. Es "el porcentaje de individuos que habría que cambiar para igualar las distribuciones" (Carabaña, 1999: 28), y se le calcula dividiendo por dos el total de las diferencias absolutas entre los marginales de la distribución de origen $(\mathrm{O})$ y los de la distribución de destino (D). Los resultados obtenidos son los mismos que se consiguen con el índice de disimilitud de Duncan. El resto de la movilidad, que comprende a los móviles del interior de la matriz de transición, es la que se considera movilidad de reemplazo. Esta última permite evaluar con mayor precisión el grado de apertura de la estructura educativa para premiar las prácticas exitosas o el fracaso en la competencia por el ascenso hacia posiciones educativas superiores. Puede considerarse a la movilidad de reemplazo como un indicador de lo que en el análisis de la movilidad educativa se denomina "permeabilidad" de la estructura educativa (véase Filgueira, 2001: 16).

La movilidad estructural hace posible el conocimiento del nivel de apertura de la estructura educativa, sin aislar (controlar) los movimientos propiciados por cambios en la estructura educativa y demográfica. En el caso de la sociedad española la movilidad educativa estructural es de $46.5 \%$, y la movilidad de reemplazo, que aísla (considera) los cambios en la estructura educativa y demográfica, de $18.4 \%$ (tabla 6). Son porcentajes que hablan de niveles bajos de rigidez del sistema de estratificación educativa, lo que supone una mayor probabilidad de que las posiciones educativas en los distintos niveles de educación se ocupen conforme a méritos y capacidad de desempeño, lo que equivale a decir que es reducida la influencia de los orígenes educativos sobre la movilidad hacia las diferentes posiciones educativas que experimenta la nueva generación, siendo en su lugar las calificaciones, la capacidad de desempeño y los logros escolares conseguidos los que la promueven.

\section{Evolución intercohortes de la movilidad educativa estructural y de reemplazo en España}

En el apartado anterior se examinó el registro de la movilidad educativa estructural y de reemplazo para el caso español en individuos de entre 25 y 65 años de edad, sin introducir diferenciación temporal alguna. Al integrar el factor tiempo mediante la variable de las cohortes de nacimiento (cohorte antigua 1935-1950, cohorte intermedia 1951-1975, y cohorte joven 1976-1986), se constata que en la cohorte antigua - que aúna a quienes iniciaron su experiencia educativa entre 1942 y 1957 - la movilidad estructural es de $19.5 \%$ y la de reemplazo es igual a $7.9 \%$, con un aumento 
significativo de la primera en 30 puntos porcentuales (49.5\%) y de la segunda en 7 puntos (14.9\%) hacia la cohorte intermedia (1951-1975) - que aúna a quienes iniciaron su experiencia educativa entre 1958 y 1982 - (tabla 3). Se puede afirmar que en la cohorte intermedia, la estructura de movilidad educativa se desrigidiza, disminuyendo la adscripción educativa entendida como influencia de los orígenes sobre los destinos educativos, y aumentando la permeabilidad educativa al experimentarse una menor reproducción acompañada de mayores oportunidades para la movilidad. En la cohorte más joven (1976-1986), y en comparación con la cohorte intermedia, la movilidad educativa estructural disminuye 4.5 puntos porcentuales, pero sigue siendo elevada si se la compara con la registrada en la cohorte antigua, mientras que la movilidad de reemplazo aumenta 12.9 puntos porcentuales. Considerando la pauta de variación incremental intercohortes de la movilidad educativa de reemplazo - que en contraste con la estructural, refleja de mejor manera el grado de apertura de la estructura educativa en términos de oportunidades para la movilidad educativa-puede afirmarse que es en la cohorte joven en la que tienen lugar las mejores condiciones en términos de mayor permeabilidad educativa y menor rigidez de la estructura de movilidad educativa (tabla 3 ).

Tabla 3. Movildiad social educativa estructural y de reemplazo

\begin{tabular}{|l|r|r|r|}
\hline España & $1935-1950$ & $1951-1975$ & $1976-1986$ \\
\hline Estructural & $19.5 \%$ & $49.5 \%$ & $45.0 \%$ \\
Reemplazo & $7.9 \%$ & $14.9 \%$ & $27.8 \%$ \\
\hline
\end{tabular}

Fuente: Elaboración propia sobre la base de la ESS, 2010.

\section{La movilidad educativa absoluta en México}

\section{Ascenso, descenso, y reproducción educativa en México}

En el análisis de los niveles de ascenso, descenso y reproducción educativa entre orígenes y destinos educativos de los/as mexicanos/as de entre 25 y 65 años de edad se observa que el ascenso educativo alcanza $53.5 \%$, el descenso $3.7 \%$ y la reproducción $42.8 \%$ (tabla 4). Del registro de estas tres dimensiones incorporadas al análisis, puede concluirse que México presenta una estructura de movilidad educativa intergeneracional menos "fluida" que la observada para el caso español, con una tasa de movilidad educativa total igual a $57.2 \%$, que se conforma en su mayor parte por movimientos hacia posiciones educativas superiores (ascenso educativo).

En el caso de la sociedad mexicana, la reproducción educativa más elevada se registra entre los hijos/as y padres con nivel educativo por debajo del nivel inferior del secundario (ISCED 0-1) (31.1\%) (tabla 4) que conforma 72.6\% del volumen total absoluto de reproducción. El registro de una mayor reproducción en el nivel educativo más bajo (ISCED 0-1) es compartido entre la sociedad mexicana y española, con la salvedad de que el porcentaje en que ocurre en la primera es superior al que se observa en la segunda: $31.1 \%$ y $22.6 \%$ respectivamente, conformando $72.6 \%$ y $64.4 \%$ del volumen total absoluto de reproducción en una y otra sociedad (tablas 1 y 4). En México, al igual 
que en la sociedad española, es en el nivel de educación terciaria completa (ISCED 5-6) en el que se registra la segunda proporción de herencia educativa más elevada, siendo en México de 4.9\% (tabla 4), equivalente a 11.4\% del volumen total absoluto de reproducción. En consonancia con lo observado, la herencia educativa se concentra en los niveles educativos "polares" (extremos) de la estructura educativa, constituyéndose así una suerte de recintos "cerrados" de reproducción intergeneracional de las posiciones educativas en la base y cumbre de la estructura, siendo más fuerte el existente en la base (nivel educativo ISCED 0-1) (tabla 4).

\begin{tabular}{|c|c|c|c|c|c|c|c|c|}
\hline \multirow{2}{*}{\multicolumn{3}{|c|}{ México }} & \multicolumn{5}{|c|}{ Nivel educativo del hijo/a (destino) } & \multirow[b]{2}{*}{ Total } \\
\hline & & & \begin{tabular}{|l|} 
ISCED 5-6 \\
\end{tabular} & ISCED 4 & ISCED 3 & ISCED 2 & ISCED 0-1 & \\
\hline \multirow{10}{*}{ 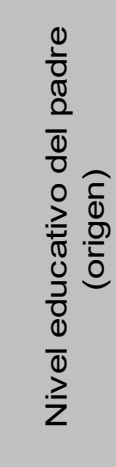 } & ISCED 5-6 & Cuenta & 319 & 21 & 59 & 16 & 0 & 415 \\
\hline & & $\%$ del total & 4.9 & 0.3 & 0.9 & 0.2 & 0 & 6.4 \\
\hline & ISCED 4 & Cuenta & 23 & 2 & 3 & 1 & 0 & 29 \\
\hline & & $\%$ del total & 0.4 & 0 & 0 & 0 & 0 & 0.4 \\
\hline & ISCED 3 & Cuenta & 127 & 8 & 174 & 49 & 8 & 366 \\
\hline & & $\%$ del total & 1.9 & 0.1 & 2.7 & 0.8 & 0.1 & 5.6 \\
\hline & ISCED 2 & Cuenta & 233 & 24 & 426 & 271 & 86 & 1040 \\
\hline & & $\%$ del total & 3.6 & 0.4 & 6.5 & 4.1 & 1.3 & 15.9 \\
\hline & ISCED 0-1 & Cuenta & 415 & 69 & 862 & 1302 & 2033 & 4681 \\
\hline & & $\%$ del total & 6.4 & 1.1 & 13.2 & 19.9 & 31.1 & 71.7 \\
\hline \multicolumn{2}{|l|}{ Total } & $\begin{array}{l}\text { Cuenta } \\
\% \text { del total }\end{array}$ & $\begin{array}{l}1117 \\
17.1\end{array}$ & $\begin{array}{r}124 \\
1.9\end{array}$ & $\begin{array}{r}1524 \\
23.3\end{array}$ & $\begin{array}{l}1639 \\
25.1\end{array}$ & $\begin{array}{r}2127 \\
32.6\end{array}$ & $\begin{array}{l}6531 \\
100.0\end{array}$ \\
\hline
\end{tabular}

Fuente: Elaboración propia sobre la base de la EMOVI, 2011.

Con relación al ascenso, los datos muestran que son los hijos/as de padres con nivel educativo ISCED 0-1 los que experimentan mayor movilidad ascendente (40.6\%) equivalente a 75.9\% del volumen total absoluto del ascenso educativo. El registro de una mayor movilidad ascendente experimentada por hijos/as de padres con nivel educativo ISCED 0-1, es una constatación compartida por la sociedad mexicana y española. De la movilidad educativa ascendente experimentada por los hijos/as de padres con nivel educativo ISCED 0-1, la mayor proporción tiene lugar hacia el nivel contiguo ISCED 2 (19.9\%), constituyendo 49\% del volumen total absoluto de ascenso desde el origen ISCED 0-1 (tabla 4). Le sigue, en contraste con el caso español donde la segunda proporción más alta de ascenso desde ISCED 0-1 tiene lugar hacia ISCED 5-6, el ascenso que tiene lugar hacia el nivel superior del secundario completo (ISCED 3) (13.2\%), equivalente a 32.5\% del volumen total absoluto de ascenso desde el origen educativo ISCED 0-1 (tabla 4). Si se suman las proporciones de movimientos educativos ascendentes que se experimentan desde el origen educativo ISCED 0-1 hacia los destinos educativos contiguos ISCED 2 e ISCED 3, se obtiene que éstos suponen 33.1\%, equivalente a $81.5 \%$ del volumen total absoluto de ascenso educativo desde ISCED $0-1$. 
En cuanto al descenso educativo en México, la mayor proporción tiene lugar para los/as hijos/as de padres con nivel de educación terciaria completa (ISCED 5-6) (1.4\%) equivalente a 37.8\% del volumen total absoluto del descenso educativo (tabla 4). Le sigue el descenso experimentado por los/as hijos/as de padres con nivel educativo inferior al secundario completo (ISCED 2) (1.3\%), constituyendo $35.1 \%$ del volumen total absoluto del descenso educativo (tabla 4). Los datos observados en la tabla de movilidad informan que la mayor proporción de descenso que tiene lugar desde el origen educativo ISCED 5-6, se efectúa hacia destinos educativos de nivel superior del secundario completo (ISCED 3) (0.9\%) constituyendo 64.3\% del volumen total absoluto de descenso desde el origen ISCED 5-6 (tabla 4). El resto del descenso desde el origen ISCED 5-6 hacia los demás destinos educativos presenta proporciones sensiblemente menores. De forma semejante a lo constatado para el caso español, el descenso experimentado por los hijos/as de padres con nivel educativo ISCED 5-6 hacia la posición educativa "polar" ubicada en el extremo opuesto e inferior de la estructura educativa, esto es, ISCED 0-1, es de carácter nulo (tabla 4).

$\mathrm{Al}$ analizar los flujos de entrada (inflows) de la movilidad educativa para la sociedad mexicana, se observa que la probabilidad de los/as hijos/as de lograr el nivel educativo superior ISCED 5-6 se encuentra influenciada por el nivel educativo alcanzado por los padres, sin evidenciarse una relación positiva entre la primer y el segundo. En contraste, el análisis de los flujos de entrada exhibe que la probabilidad de los/as hijos/as de superar los dos niveles educativos más bajos (ISCED 0-1 e ISCED 2) se encuentra condicionada bajo una relación positiva con el nivel educativo alcanzado por el padre, a saber: a menor nivel educativo del padre, menor la probabilidad de que los/as hijos/ as logren superar los dos niveles educativos más bajos (gráfico II). 


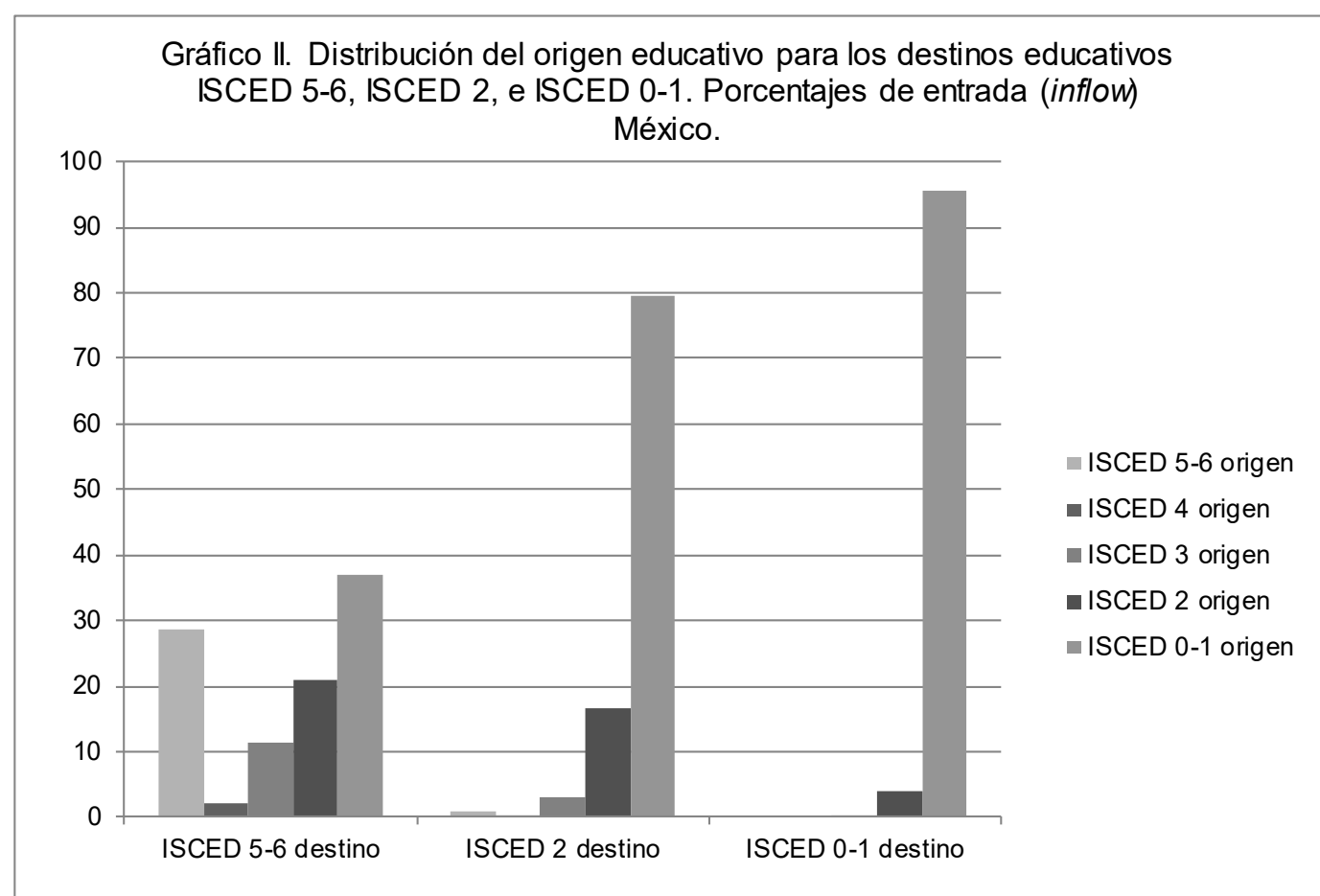

Fuente: Elaboración propia sobre la base de la EMOVI, 2011.

Evolución intercohortes de ascenso, descenso y reproducción educativa en México

Para el caso de la sociedad mexicana se definen tres cohortes de nacimiento, una cohorte antigua que comprende a quienes han nacido entre los años 1947 y 1960, y que al año $2011^{6}$ tienen entre 64 y 51 años de edad, una cohorte intermedia que aúna a quienes han nacido entre 1961 y 1975, y que al 2011 tiene entre 50 y 36 años de edad, y una cohorte joven que abarca a quienes han nacido entre 1976 y 1986, y que al 2011 tienen entre 35 y 25 años de edad. En el análisis del ascenso, descenso y reproducción educativa, tras la introducción del factor temporal mediante la variable de las cohortes de nacimiento, se observa que en la cohorte antigua (1947-1960) la reproducción es de 64.1\%, el ascenso de $33.2 \%$ y el descenso educativo de $2.7 \%$ (tabla 5). En perspectiva comparada con las dos cohortes más jóvenes, la cohorte antigua registra la reproducción educativa más elevada, con una influencia de los orígenes sobre los destinos educativos en términos de posiciones heredadas que resulta ser la más fuerte. La cohorte antigua registra la más baja permeabilidad educativa en la evolución intercohortes, con una tasa de movilidad educativa total de $35.9 \%$.

\footnotetext{
${ }^{6}$ Año en que culmina el relevamiento de la información de la encuesta empleada para el análisis de la movilidad social educativa en México.
} 
Tabla 5. Dimensiones movildiad social educativa absoluta

\begin{tabular}{|l|r|r|r|}
\hline México & $1947-1960$ & $1961-1975$ & $1976-1986$ \\
\hline Reproducción & $64.1 \%$ & $39.5 \%$ & $35.6 \%$ \\
Ascendente & $33.2 \%$ & $57.8 \%$ & $59.1 \%$ \\
Descendente & $2.7 \%$ & $2.7 \%$ & $5.2 \%$ \\
& $100.0 \%$ & $100.0 \%$ & $100.0 \%$ \\
\hline
\end{tabular}

Fuente: Elaboración propia sobre la base de la EMOVI, 2011.

En la cohorte intermedia (1961-75), y en relación con la cohorte antigua, la reproducción educativa (39.5\%) decrece 24.6 puntos porcentuales, 12.4 puntos porcentuales menos de lo que decrece en España para las mismas cohortes. El ascenso educativo (57.8\%) aumenta 24.6 puntos porcentuales, 12 puntos porcentuales menos de lo que aumenta en España para las mismas cohortes. Y el descenso educativo se mantiene constante (2.7\%) (tabla 5). La proporción en que disminuye la reproducción educativa en la cohorte intermedia respecto a la cohorte antigua lleva a un incremento proporcional del ascenso, sin afectar el descenso educativo. En consecuencia, se atenúa la adscripción educativa en términos de posiciones educativas heredadas y aumenta la permeabilidad educativa con una tasa de movilidad educativa total que pasa a ser del orden de $60.5 \%$ (tabla 5).

Con relación a la cohorte más joven (1976-86), y en comparación con la cohorte intermedia, la reproducción educativa decrece 3.9 puntos porcentuales, con lo que se cierra una pauta decreciente de reproducción intercohortes $(64.1 \%, 39.5 \%$ y $35.6 \%$, respectivamente), tendencia que, con diferencia en cuanto a las magnitudes, también es observada en la sociedad española. El ascenso educativo en la cohorte joven comparada con la cohorte intermedia, aumenta 1.3 puntos porcentuales, definiendo una pauta incremental de ascenso intercohortes $(33.2 \%, 57.8 \%, 59.1 \%$, respectivamente) que, con diferencia en cuanto a las magnitudes, es también compartida por la sociedad española. En cuanto al descenso educativo (5.2\%), se rompe con la pauta constante, incrementando en 2.5 puntos porcentuales (tabla 5). La adscripción educativa disminuye y la permeabilidad educativa aumenta, con una tasa de movilidad educativa total de $64.3 \%$ (tabla 5).

\section{Movilidad educativa estructural y de reemplazo en México}

Al igual que en el análisis de la movilidad educativa intergeneracional en España, en el estudio de la movilidad educativa intergeneracional en México es posible diferenciar entre movilidad estructural y de reemplazo. La movilidad educativa estructural, que permite una valoración del grado de apertura de la estructura educativa sin aislar (controlar) la influencia de los cambios en la estructura educativa y demográfica sobre los movimientos entre orígenes y destinos educativos ISCED, es de $39.1 \%, 7.4$ puntos porcentuales menos que la registrada para el caso español (46.5\%) (tabla 6). La movilidad de reemplazo, que contribuye a la valoración del grado de apertura de la estructura 
educativa en términos de su capacidad para recompensar las prácticas exitosas o de fracaso en la competencia por el ascenso hacia destinos educativos superiores, controlando los cambios en la estructura educativa y demográfica, es igual a $18.1 \%$, próxima a la observada en la sociedad española (18.4\%) (tabla 6). En perspectiva comparada con el caso español, México presenta un nivel de adscripción educativa más alto y un grado de permeabilidad más bajo. En el sistema de estratificación educativa mexicano los orígenes educativos condicionan con mayor fuerza los destinos educativos que en el caso español.

Tabla 6. Movilidad estructural y de reemplazo

\begin{tabular}{|l|r|r|}
\hline & España & \multicolumn{2}{c|}{ México } \\
\hline Estructural & 46.5 & 39.1 \\
Reemplazo & 18.4 & 18.1 \\
\hline
\end{tabular}

Fuente: Elaboración propia (ESS 2010, y EMOVI 2011).

\section{Evolución intercohortes de la movilidad educativa estructural y de reemplazo en México}

En el análisis de la movilidad educativa estructural y de reemplazo para la sociedad mexicana tras la introducción del factor temporal mediante la variable de las cohortes de nacimiento, se observa que en la cohorte antigua (1947-1960) - que aúna a quienes iniciaron su experiencia educativa entre 1953 y 1967 - la movilidad estructural es igual a $25.3 \%$ y la de reemplazo $10.6 \%$. En la cohorte intermedia (1961-1975) - que comprende a quienes iniciaron su experiencia educativa entre 1968 y 1982 - la movilidad estructural aumenta 19.1 puntos porcentuales $(44.4 \%)$ y la de reemplazo 6.5 puntos (17.1\%) (tabla 7). Es posible afirmar que en la cohorte intermedia se atenúa el condicionamiento de los orígenes sobre los destinos educativos, al tiempo que disminuye la herencia de posiciones educativas y aumentan las oportunidades para la desrigidización de la estructura de movilidad educativa. En la cohorte joven (1976-1986), y respecto a la cohorte intermedia, la movilidad educativa estructural disminuye 3.7 puntos porcentuales, aunque se mantiene superior a la que se observa en la cohorte antigua, al tiempo que la movilidad de reemplazo se incrementa 6.6 puntos porcentuales. En la comparación intercohortes de la movilidad educativa de reemplazo, que da cuenta del grado de apertura de la estructura educativa en términos de oportunidades ofrecidas a los miembros de una sociedad para el ascenso y descenso educativo, se constata que es en la cohorte joven en la que tiene lugar el mayor grado de permeabilidad y la menor de adscripción educativa (tabla 7). 
César Augusto Ricardi Morgavi

Tabla 7. Movilidad social educativa estructural y de reemplazo

\begin{tabular}{|l|r|r|r|}
\hline México & $1947-1960$ & $1961-1975$ & $1976-1986$ \\
\hline Estructural & $25.3 \%$ & $44.4 \%$ & $40.7 \%$ \\
Reemplazo & $10.6 \%$ & $17.1 \%$ & $23.7 \%$ \\
\hline
\end{tabular}

Fuente: Elaboración propia sobre la base de la EMOVI, 2011.

\section{Movilidad educativa relativa en España y México}

El estudio de la movilidad educativa relativa se basa en la evaluación de una serie de indicadores que se aplican en el análisis comparativo entre modelos log-lineales. Entre los indicadores que aquí se consideran se encuentra el estadístico de la bondad de ajuste $\mathrm{L}^{2}$, cuya probabilidad asociada se emplea como prueba de hipótesis, en la que la hipótesis nula (H0) afirma la existencia de un ajuste entre el modelo teórico de movilidad y los datos observados en la tabla de movilidad educativa. La hipótesis alternativa (H1) afirma la existencia de un desajuste, dada la existencia de diferencias estadísticamente significativas, entre los datos esperados con modelo teórico puesto a prueba y los datos observados en la tabla de movilidad educativa. La hipótesis nula se acoge cuando la probabilidad asociada al estadístico $\mathrm{L}^{2}$ es mayor o igual a $5 \%(\alpha \geq 0.05)$, satisfaciéndose así el principio de suficiencia (existencia de bondad de ajuste del modelo teórico).

Si se acoge la hipótesis nula, el siguiente paso consiste en evaluar el grado de adecuación del modelo teórico respecto a los datos observados con base en la comparación con el modelo de referencia (baseline model). El modelo que por definición se emplea como modelo de referencia es el denominado modelo saturado. Se trata del modelo teórico que mejor ajusta a los datos, satisfaciendo el criterio de suficiencia, pero siendo al mismo tiempo el menos parsimonioso al emplear todos los parámetros de ajuste a los datos disponibles. En consecuencia, es posible asumir como modelo de referencia el denominado modelo de independencia condicional, el cual formula la hipótesis de la existencia de independencia estadística entre los orígenes y los destinos educativos, es decir, afirma la existencia de movilidad educativa perfecta, situación ideal que adolece de correlato con la realidad observada en la sociedad. Cuando el modelo de independencia condicional es asumido como modelo de referencia, y el modelo teórico que se pone a prueba presenta una bondad de ajuste $\mathrm{L}^{2} \mathrm{y}$ un número de grados de libertad inferiores a los del modelo de referencia (modelo de independencia condicional), se concluye que el modelo es más parsimonioso que el modelo de referencia, y por consiguiente, ajusta mejor y es preferible. Además de satisfacer el principio de suficiencia, el modelo que se prefiere debe satisfacer el principio de simplicidad o parsimonia, según el cual el modelo que da cuenta de las características de los datos empleando el menor número de parámetros posible es el que mejor se ajusta a los datos observados. El método que se sigue para evaluar la adecuación de los modelos se basa en ir calculando las diferencias entre las bondades de ajuste $\mathrm{L}^{2}$ de los modelos que se comparan tanto entre sí como respecto al modelo de referencia. 
El análisis se complementa con la integración de un conjunto de indicadores que refuerzan la precisión de la evaluación comparativa de los modelos teóricos de movilidad educativa. Es posible por tanto contar con mayor información que la que proporciona el estadístico de bondad de ajuste $\mathrm{L}^{2}$, para decidir en torno al grado de ajuste y adecuación de los modelos teóricos respecto a los datos observados de movilidad educativa. Uno de estos indicadores es el denominado Criterio de Información Bayesiano (BIC, de sus siglas en inglés Bayesian Information Criterion) que contribuye a evaluar la relación en verosimilitud entre dos modelos puestos en comparación entre sí, es decir, a sopesar la plausibilidad de los modelos. Cuanto menor es el valor de BIC que presente un modelo, mejor satisface el principio de simplicidad. Un segundo indicador complementario en la evaluación de los modelos es el índice de disimilitud D, que sintetiza el nivel de discrepancia entre la distribución de los datos observados y la de los datos esperados bajo el modelo teórico puesto a prueba. El índice de disimilitud D informa de la proporción de casos que deberían ser reclasificados para que se logre la situación de independencia estadística, por lo que cuanto más bajo es el valor registrado por el índice, mejor es el ajuste del modelo a los datos observados.

Un tercer indicador complementario que sirve a la evaluación comparada de los modelos de movilidad educativa es el coeficiente de determinación múltiple pseudo $\mathrm{R}^{2}$ de Goodman. El coeficiente informa de la capacidad del modelo teórico para dar cuenta de las asociaciones observadas entre las variables analizadas. Cuanto mayor es el valor del coeficiente pseudo $\mathrm{R}^{2}$ de Goodman, mejor explica el modelo teórico los datos observados. Finalmente, un cuarto indicador complementario en la evaluación comparativa de los modelos es el estandarizador de Schwartz L ${ }^{2}$ (S). El estandarizador pone en relación más de dos variables al mismo tiempo y mejora, al normalizar, la medición realizada por el estadístico de la bondad de ajuste $\mathrm{L}^{2}$, que suele ser sensible al tamaño de la muestra empleada. El valor del estandarizador de Schwartz L ${ }^{2}$ (S) se utiliza como prueba de hipótesis de la bondad de ajuste, por lo que al interpretar su probabilidad asociada se puede determinar la acogida de la hipótesis nula — cuando es igual o mayor a 5\% o 0.05 nivel de significación — o su rechazo.

En el análisis de la movilidad educativa intergeneracional relativa en la sociedad española y en la mexicana se ponen en relación las variables de orígenes educativos (O) (nivel educativo de los padres), destinos educativos (D) (nivel educativo de los/as hijos/as), y cohortes de nacimiento (C). Los modelos que se evalúan son, el modelo de independencia condicional, el modelo de fluidez constante y el modelo de la diferencia uniforme (unidiff). El modelo de independencia condicional se asume como modelo de referencia, siendo particularmente relevante en la evaluación del grado de ajuste del modelo de fluidez constante. En el caso de España, el modelo de independencia condicional exhibe una bondad de ajuste $\mathrm{L}^{2}$ igual a 365.563 , para 48 grados de libertad, con una probabilidad asociada (Sig.) inferior a 5\% (tabla 8). Cuando se ajusta la bondad de ajuste $\mathrm{L}^{2}$ por el estandarizador de Schwartz, ésta disminuye a 131.569, con una probabilidad asociada aún inferior al 5\%. Adicionalmente, el modelo presenta un índice de disimilitud igual a $15.6 \%$, y un BIC de 
13.30, ambos con los valores más elevados entre los modelos comparados. Por consiguiente, se concluye el desajuste del modelo de independencia condicional a los datos observados, no satisfaciendo los principios de suficiencia y parsimonia. El rechazo del modelo equivale a afirmar que existe condicionamiento de los orígenes sobre los destinos educativos.

El modelo de fluidez constante, que formula la hipótesis de la existencia de un patrón de movilidad y reproducción educativa que es constante a través del tiempo, de una generación a otra, presenta un valor de bondad de ajuste $\mathrm{L}^{2}$ igual a 15.793 para 32 grados de libertad, con una probabilidad asociada (Sig.) superior a 5\% (tabla 8). Con un BIC igual a -219.05 , por debajo del registrado para el modelo de independencia condicional, y un índice de disimilitud que es el más bajo en la comparación entre modelos (1.9\%), el modelo de fluidez constante explica un 95.7\% mejor los datos observados que el modelo de independencia condicional (tabla 8). Cuando se normaliza la bondad de ajuste $\mathrm{L}^{2}$ del modelo de fluidez constante mediante el estandarizador de Schwartz, ésta pasa a ser de 27.735, para 32 grados de libertad, con una probabilidad asociada superior a 5\% (tabla 8). Por consiguiente, se concluye el ajuste del modelo de fluidez constante a los datos observados, satisfaciendo los criterios de suficiencia y simplicidad - siendo el más parsimonioso de entre los modelos comparados - y acogiéndose la hipótesis de la existencia de una pauta de movilidad y reproducción educativa que se presenta invariante de una cohorte a otra.

Si el modelo de fluidez constante formula la hipótesis de la existencia de un patrón de movilidad y reproducción educativa que se presenta constante a través del tiempo, el modelo de la diferencia uniforme (unidiff) ${ }^{7}$ formula la hipótesis de la existencia de una pauta monótona (cambio uniforme) entre orígenes y destinos educativos cuando se comparan las generaciones (cohortes), pudiéndose estimar a través del mismo la fuerza de la fluidez-rigidez educativa. El modelo de la diferencia uniforme sirve para refrendar o matizar la hipótesis de la existencia de un patrón de movilidad constante que formula el modelo de fluidez constante. El modelo unidiff registra una bondad de ajuste $\mathrm{L}^{2}$ igual a 43.200 , para 45 grados de libertad, con una probabilidad asociada superior a $5 \%$ (tabla 8). Cuando se normaliza la bondad de ajuste $\mathrm{L}^{2}$ mediante el estandarizador de Schwartz, ésta aumenta a 44.526, con una probabilidad asociada superior a 5\% (tabla 8). Con un BIC que es el más bajo de los modelos comparados (-287.05), un índice de disimilitud igual a 3.5\%, y explicando los datos observados $88.2 \%$ mejor que el modelo de independencia condicional, se concluye que el modelo de la diferencia uniforme se ajusta a los datos observados en la tabla de movilidad educativa. Se acoge por tanto la hipótesis de la existencia de un patrón de cambio uniforme entre orígenes y destinos educativos a través de las cohortes.

\footnotetext{
${ }^{7}$ El análisis del modelo unidiff considera los valores de "asociación uniforme" (uniform association) en lugar de los valores de "interacción completa" (full interaction).
} 
Análisis comparativo de la movilidad social educativa intergeneracional en España y México

Tabla 8. Movilidad educativa relativa. Modelos log-lineales, España.

\begin{tabular}{|c|c|c|c|c|c|c|c|c|}
\hline Modelo & $L^{2}$ & $\begin{array}{l}\text { Grados de } \\
\text { libertad }\end{array}$ & Sig. & BIC & Pseudo $R^{2}$ & $\begin{array}{l}\text { Índice de } \\
\text { disimilitud }\end{array}$ & $L^{2}(S)$ & Sig. $L^{2}(S)$ \\
\hline \multicolumn{9}{|l|}{ Orígen, Destino y Cohorte } \\
\hline Saturado [O D C] & 0.000 & 0 & 1.000 & 0.00 & $100.0 \%$ & $0.0 \%$ & 0.000 & 1.000 \\
\hline Indep. condicional $[0 \mathrm{C}][\mathrm{D} C]$ & 365.563 & 48 & 0.000 & 13.30 & $0.0 \%$ & $15.6 \%$ & 131.569 & 0.000 \\
\hline Fluidez constante $[0 \mathrm{D}][\mathrm{O} C][\mathrm{D} C]$ & 15.793 & 32 & 0.993 & -219.05 & $95.7 \%$ & $1.9 \%$ & 27.735 & 0.682 \\
\hline Unidiff & 43.200 & 45 & 0.550 & -287.05 & $88.2 \%$ & $3.5 \%$ & 44.526 & 0.491 \\
\hline
\end{tabular}

Fuente: Elaboración propia sobre la base de la European Social Sunvey, 2010.

Habiéndose acogido el modelo de la diferencia uniforme, el siguiente paso consiste en interpretar los coeficientes beta $(\beta)$ o parámetros phi $(\varphi)$ que ofrece el modelo en aras de conocer el comportamiento de la movilidad educativa relativa en términos de variabilidad a través de las cohortes y de grado de fluidez-rigidez educativa que caracteriza al patrón. Asumiendo la cohorte antigua de los nacidos entre 1935 y 1950 como cohorte de referencia, se observa la existencia de una pauta de escasa variabilidad hacia la cohorte intermedia (1951-1975) (coeficiente de 0.9149) y de mayor variabilidad hacia la cohorte joven (1976-1986) (coeficiente de 0.6823) en la que se constata una intensificación de la fluidez educativa (tabla 9). El comportamiento del patrón de fluidez educativa, teniendo en cuenta las limitaciones que implica trabajar con tan sólo tres cohortes, es de baja variabilidad entre las dos cohortes más viejas (antigua e intermedia), y de una variabilidad acentuada hacia la cohorte más joven. Se constata un patrón que indica que la fluidez educativa aumenta entre las cohortes - valores del coeficiente por debajo de 1 indican fluidez, mientras que valores superiores a 1, rigidez-y se intensifica en la cohorte joven (1976-1986).

Tabla 9. España (ISCED)

Parámetros Phi (Unidiff)

\begin{tabular}{|l|c|}
\hline Cohortes & Parámetros \\
\hline Nacidos entre 1935-1950 & 1.0000 \\
Nacidos entre 1951-1975 & 0,9149 \\
Nacidos entre 1976-1986 & 0,6823 \\
\hline
\end{tabular}

Fuente: Elaboración propia a partir de la European Social Survey, 2010. 
El análisis de la movilidad educativa relativa para el caso de México presenta un modelo de independencia condicional con un valor de bondad de ajuste $\mathrm{L}^{2}$ igual a 2125.298, para 48 grados de libertad, y una probabilidad asociada inferior a $5 \%$ (tabla 10). Al normalizar la bondad de ajuste $\mathrm{L}^{2}$ por medio del estandarizador de Schwartz, ésta se reduce a 460.851, para 48 grados de libertad, con una probabilidad asociada inferior a 5\%. Con un BIC y un índice de disimilitud (1703.65 y 19.8\%, respectivamente) que son los más elevados entre los modelos puestos en comparación, puede afirmarse que el modelo de independencia condicional no satisface los principios de suficiencia y parsimonia, por lo que se concluye su desajuste a los datos observados. Puede afirmarse que existe asociación estadísticamente significativa entre los orígenes y destinos educativos.

$\mathrm{El}$ análisis de la fluidez educativa con base en el modelo de fluidez constante registra una bondad de ajuste $\mathrm{L}^{2}$ igual a 121.337, para 32 grados de libertad, con una probabilidad asociada inferior a 5\% (tabla 10). Si bien el modelo de fluidez constante muestra un BIC y un índice de disimilitud (-159.76 y $2.7 \%$, respectivamente) que son los más bajos entre los modelos puestos en comparación, así como explica los datos observados $94.3 \%$ mejor que el modelo de independencia condicional, se concluye que el modelo no satisface el principio de suficiencia, no ajustándose a los datos observados (tabla 10). Puede afirmarse la ausencia de un patrón de movilidad y reproducción educativa que se presente invariante entre las cohortes de nacimiento para la sociedad mexicana.

El modelo de la diferencia uniforme (unidiff) registra un valor de bondad de ajuste igual a 370.800 , para 45 grados de libertad, con una probabilidad asociada inferior a $5 \%$. Cuando el estadístico de la bondad de ajuste $\mathrm{L}^{2}$ se ajusta por el estandarizador de Schwartz, se reduce a 109.751, para 45 grados de libertad, con una probabilidad asociada inferior a 5\% (tabla 10). Con un BIC igual a -24.49 , un índice de disimilitud de $7 \%$, y explicando los datos observados $82.6 \%$ mejor que el modelo de independencia condicional, el modelo de la diferencia uniforme no logra satisfacer los principios de suficiencia y parsimonia. El modelo unidiff muestra desajuste a los datos observados en la tabla de movilidad educativa, por lo que se concluye la inexistencia de un patrón de cambio uniforme entre orígenes y destinos educativos a través de las generaciones (cohortes).

Tabla 10. Movilidad educativa relativa. Modelos log-lineales, México.

\begin{tabular}{|l|r|r|r|r|r|r|r|r|}
\hline \multicolumn{1}{|c|}{ Modelo } & $\mathrm{L}^{2}$ & $\begin{array}{r}\text { Grados de } \\
\text { libertad }\end{array}$ & \multicolumn{1}{c|}{ Sig. } & BIC & Pseudo $\mathrm{R}^{2}$ & $\begin{array}{l}\text { Índice de } \\
\text { disimilitud }\end{array}$ & $\mathrm{L}^{2}(\mathbf{S})$ & Sig. $\mathrm{L}^{2}(\mathbf{S})$ \\
\hline \multicolumn{1}{|c|}{ Orígen, Destino y Cohorte } & & & & & & & & \\
\hline Saturado [O D C] & 0.000 & 0 & 1.000 & 0.00 & $100.0 \%$ & $0.0 \%$ & 0.000 & 1.000 \\
\hline Indep. condicional [O C] [D C] & 2125.298 & 48 & 0.000 & 1703.65 & $0.0 \%$ & $19.8 \%$ & 460.851 & 0.000 \\
\hline Fluidez constante [O D] [O C] [D C] & 121.337 & 32 & 0.000 & -159.76 & $94.3 \%$ & $2.7 \%$ & 49.755 & 0.023 \\
\hline Unidiff & 370.800 & 45 & 0.000 & -24.49 & $82.6 \%$ & $7.0 \%$ & 109.751 & 0.000 \\
\hline
\end{tabular}

Fuente: Elaboración propia sobre la base de la EMOVI, 2011. 


\section{Conclusiones}

Del análisis comparativo de movilidad educativa intergeneracional en España y México se sintetizan los siguientes hallazgos. En lo concerniente al análisis de la movilidad educativa absoluta en términos de niveles de ascenso, descenso y reproducción educativa para individuos de entre 25 y 65 años de edad, la sociedad española contrasta con la mexicana, presentando una menor herencia de posiciones educativas ( 7.7 puntos porcentuales menos) una mayor movilidad educativa ascendente (6.8 puntos porcentuales mayor) y descendente, que lo es por apenas 0.9 puntos porcentuales. Los resultados hablan de niveles de adscripción educativa más bajos y permeabilidad educativa más alta en la sociedad española respecto a la mexicana, con tasas de movilidad educativa totales de $64.9 \%$ y $57.2 \%$, respectivamente. Los hallazgos obtenidos son consistentes con los obtenidos por Mediavilla y Calero (2010), en cuyo análisis se observa una nítida relación positiva entre la educación de los padres (orígenes) y el nivel educativo logrado por hijos/as (destinos), relación que los autores encuentran más laxa en el caso español que en el mexicano, acompañada de una movilidad educativa intergeneracional que resulta más alta en el primero. ${ }^{8}$

El caso español comparte con el mexicano un registro de la mayor proporción del volumen total absoluto de reproducción educativa en el nivel educativo más bajo (ISCED 0-1), no obstante, puestos en comparación, resulta ser más fuerte la observada en la sociedad mexicana. Asimismo, comparten ambas sociedades el que la segunda mayor proporción del volumen total absoluto de reproducción educativa tiene lugar en el nivel educativo más alto (ISCED 5-6), siendo en este caso más fuerte la observada en España. En ambas sociedades se observa que la reproducción educativa tiende a concentrarse en la cumbre y en la base de la estructura educativa, siendo más intensa la que tiene lugar en la base, y en México más aún que en España. Los resultados hablan de las grandes ventajas que en ambas sociedades presentan los individuos cuyos padres han completado una educación superior universitaria. En este sentido, la movilidad educativa ascendente cuando se tiene por origen educativo el nivel de ISCED 0-1, fuerte en ambas sociedades, es del tipo corta (movimientos de una sola posición, categoría, o nivel) en España como en México, teniendo lugar hacia un destino de nivel contiguo ISCED 2. No obstante, en España tiene lugar una alta proporción de movilidad ascendente de tipo extensa (movimientos desde el nivel más bajo hacia el nivel más alto recorriendo la estructura educativa desde una posición extrema a la otra) desde un origen ISCED 0-1 hacia destinos ISCED 5-6, mientras que en el caso de México la alta proporción refiere a una movilidad de tipo larga (movimientos de entre dos y tres posiciones, categoría o nivel) desde

${ }^{8}$ Mediavilla y Calero (2010) hallan una correlación igual a 0.552 entre el nivel educativo del padre y el nivel educativo de los/as hijos/as para la sociedad mexicana, mientras que el obtenido para la sociedad española es 0.42 en Carabaña (1999), 0.45 en Sánchez (2004), 0.43 Calero y Escardíbul (2005). Cuanto mayor es el valor del coeficiente de correlación, mayor es la rigidez educativa de la sociedad estudiada. 
un origen ISCED 0-1 hacia un destino ISCED 3. Con ello se quiere significar que en la sociedad española existe mayor probabilidad de acceder y completar una educación de tipo universitaria, procediendo de padres que tienen por máximo nivel educativo primaria completa, que en México. En cuanto al descenso educativo, en ambas sociedades la mayor proporción de movilidad educativa descendente tiene lugar desde el origen educativo ISCED 5-6 - siendo más elevada en el caso español que mexicano- lo que se asocia con posibles ceiling effects en virtud de que no existe una categoría educativa más alta que ISCED 5-6 a la que se pueda ascender y, en contraste, si un resto a las que se puede descender.

Cuando se analiza la movilidad educativa absoluta introduciendo el factor temporal por medio de la variable de cohortes, se constata que ambas sociedades comparten un patrón de reproducción educativa decreciente intercohortes, con un "salto" decreciente significativo desde la cohorte antigua hacia la intermedia de 37 puntos porcentuales en el caso español y 24.6 en el mexicano, que se atenúa desde la cohorte intermedia hacia la joven con 8.4 puntos en el caso de España y 3.9 en el mexicano. La movilidad educativa ascendente presenta una pauta incremental intercohortes en ambas sociedades. En España el "salto" incremental del ascenso educativo es de 36.6 puntos porcentuales de la cohorte antigua a la intermedia, mientras que en México es de 24.6 puntos para las mismas cohortes. Por su parte, el descenso educativo tiene su "salto" incremental desde la cohorte intermedia a la joven. Por tanto, puede afirmarse que el descenso educativo va a aumentar una vez que se estabiliza el ascenso (aumentando) y la reproducción educativa (disminuyendo). Una primera conclusión es que de las tres aristas de la movilidad educativa absoluta que se analizan (ascenso, descenso y reproducción educativa), las diferencias entre la sociedad española y la mexicana refieren a las magnitudes mientras que las semejanzas a las tendencias a través del tiempo.

En el caso de México, las variaciones que resultan positivas (reducción de la reproducción, aumento del ascenso y descenso educativo invariante) desde la cohorte antigua a la intermedia, se explican por una trayectoria educacional de los nacidos entre 1961 y 1975 que tiene lugar durante fines de la década de los sesenta, y durante los setenta y ochenta, en un contexto de expansión educativa que comienza a estancarse con el agotamiento de la expansión educativa, la crisis económica y la reducción del gasto social en educación que tiene lugar durante los años ochenta, y cuyo efecto es aún incipiente sobre la cohorte intermedia pero evidente sobre los nacidos en la cohorte joven (1976-1986) cuyas trayectorias educativas son experimentadas hacia fines de los ochenta y durante los noventa, en un contexto de ralentización de la reducción de la reproducción y del incremento del acenso educativo, acompasados por un aumento del descenso educativo. La crisis y el ajuste estructural que tuvo lugar en la sociedad mexicana afectaron el logro educativo de los nacidos en la cohorte joven. Estos resultados son consistentes con los hallazgos de Torche (s.a.), Binder (1999) y Binder y Woodruff (2002), que refuerzan la tesis del estancamiento educativo de la cohorte de nacidos que experimentan su trayectoria educativa en el contexto mexicano de crisis económica. 
En el caso de España, y en contraste con México, se observa una mayor reducción intercohortes de la reproducción educativa así como un mayor incremento intercohortes de la tasa de movilidad educativa total, hallazgo que es consistente con los resultados obtenidos por Mediavilla y Calero (2010), quienes calculan el índice de inmovilidad educativa en México, que es igual a 0.39, frente al 0.18 de España (Mediavilla y Calero, 2006), concluyendo la existencia de una movilidad educativa relativa más baja y un sistema educativo que reproduce con mayor fuerza las desventajas sociales de partida en el país latinoamericano frente al europeo.

El análisis de la movilidad educativa relativa aplicando tres modelos log-lineales (independencia condicional, fluidez constante y diferencia uniforme) permite concluir que en la sociedad española, a diferencia de la mexicana, se identifica un patrón de movilidad y reproducción educativa que se muestra constante de una generación a otra, siendo en la cohorte joven (1976-1986) en la que se registra la mayor fluidez educativa (desrigidización) que se observa también, aunque más débil, en la cohorte intermedia (1951-1975). En el caso de la sociedad mexicana es posible afirmar la inexistencia de una pauta de movilidad y reproducción educativa que sea constante de una generación a otra. Este hallazgo en la sociedad mexicana es consistente con lo observado por Torche (s.a.), que mediante la aplicación de los modelos de diferencia uniforme y fluidez constante, concluye que el cambio en la movilidad educacional en México es débil, predominando la estabilidad temporal. El análisis de la movilidad educativa relativa desarrollado en este artículo se fortalecería con la futura integración de modelos log-lineales como el de esquinas quebradas de Hout (1983), que hipotetiza la existencia de un "recinto cerrado" en los niveles más elevados y en los más bajos de la estructura educativa sugiriendo la existencia de una movilidad educativa bastante estrecha, el topológico de Hauser (1978) que hipotetiza la existencia de una mayor rigidez y reproducción en los niveles educativos más bajos respecto a los más altos —en los que tendría lugar una mayor fluidez educativa - y el de cruce (Powers y Xie, 2000), que hipotetiza que la probabilidad de que un individuo experimente movilidad educativa desde un nivel a otro se encuentra determinada por la dificultad de cruzar las barreras que separan esos niveles.

\section{Bibliografía}

Beyer, H. y C. Le Foulon (2002). "Un recorrido por las desigualdades salariales en Chile". En: Estudios Públicos, núm. 85, pp. 139-175.

Binder, M. (1999). "Schooling indicators during Mexico's 'Lost Decade”'. En: Economic Education Review, núm. 18, pp. 183-199.

- y C. Woodruff (2002). "Inequality and intergenerational mobility in schooling: The case of Mexico" En: Economic Development and Cultural Change. Vol. 50, núm. 2, pp. 249-267.

Birdsall, N. y J. L. Lodoño (1998). "No tradeoff: Efficient growth via more equal human capital accumulation". En: C. Birdsall, N., C. Graham y R. Sabot (eds.). Beyond tradeoffs: Make reform and equitable growth in Latin America. Washington: IADB. 
Boado, M. (2008). "La movilidad social en el Uruguay contemporáneo”. Tesis doctoral. Río de Janeiro: Instituto Universitario de Pesquisas de Río de Janeiro, IUPERJ-UDELAR.

Calero, J. (2006). "Desigualdades tras la educación obligatoria: Nuevas evidencias". Documento de Trabajo de la Fundación Alternativas, núm. 83.

— y J. O. Escardíbul (2005). "Financiación y desigualdades en el sistema educativo y de formación profesional en España”. En: Navarro, V. (ed.). La situación social de España. Madrid: Biblioteca Nueva-Fundación Largo Caballero, pp. 337-384.

— S. Waisgrais y M. Mediavilla (2007). "Desigualdades socioeconómicas en el sistema educativo español”. Colección Investigación del CIDE, núm. 176.

— y Á. Quiroga (2008). Sociedad desigual ¿Educación desigual? Sobre las desigualdades en el sistema educativo español. Colección Investigación del CIDE, núm. 7.

Carabaña, J. (1999). Dos estudios sobre movilidad intergeneracional. Madrid: Fundación Argentaria-Visor.

Cragg, M. y M. Epelbaum (1996). "Why has wage dispersion grown in Mexico? Is it the incidence of reforms or the growing demand for skills?". En: Journal of Development Economics, núm. 51, pp. 99-116.

Duryea, S. y C. Pages (2002). "Achieving high labor productivity in Latin America: Is education enough?". Washington: IADB, mimeo.

Escobar Latapí, A. (1993). "Reestructuración económica y desigualdad social en México: el caso de Guadalajara". Ponencia presentada al Primer Congreso Latinoamericano de Sociología del Trabajo. El Colegio de México, noviembre de 1993.

- (1995). "Movilidad, restructuración, y clase social en México. El caso de Guadalajara". En: Estudios Sociológicos. Vol. 13, núm. 38, pp. 309-339.

— y Fernando Cortés (2002). "Modelos de acumulación de capital y movilidad social: un estudio del México urbano". México: Mimeo.

Filgueira, C. (2001). "La actualidad de viejas temáticas: sobre los estudios de clase, estratificación y movilidad social en América Latina”. En: Serie Políticas Sociales de la CEPAL, núm. 51.

Goldthorpe, J. H. (1980) Social mobility and class structure in modern Britain. Oxford: Clarendon. Hauser, R. (1978). "Some exploratory methods for modelling mobility tables and other crossclassified data". En: CDE Working Paper, núm. 19.

Hout, M. (1983). Mobility tables. Beverly Hills: Sage.

Martínez-Celorrio, X. y A. Marín Saldo (2010). Educació i mobilitat social a Catalunya. Barcelona: Fundació Jaume Bofill.

Mediavilla, M. y J. Calero (2006) "Movilidad educativa en España. Un análisis con datos del PHOGUE”. En: Investigaciones de Economía de la Educación, núm. 1, pp. 25-34.

- (2010). "Movilidad educativa en Latinoamérica, un estudio para seis países". En: Revista Española de Educación Comparada, núm. 16, pp. 287-303. 
Powers, D. e Y. Xie (2000). Statistical methods for categorical data analysis. San Diego: Academic Press.

Psacharopoulos, G. y H. Patrinos (2002). Returns to investment in education: A further update. World Bank Policy Research Paper, núm. 2881.

Ricardi, A. (2012) "Movilidad educativa en España. Modelos explicativos y perspectiva comparada". Tesis de maestría en investigación sociológica. Barcelona, Departamento de Teoría Sociológica, Filosofía del Derecho y Metodología de las Ciencias Sociales, Universidad de Barcelona.

- (2014) "Bases para el estudio comparativo de la movilidad social sobre una selección de sociedades democráticas Europa y América Latina”. En: IXAYA, núm. 7, pp. 13-46.

- (2016) "Panorama reciente del bienestar en México: reformas y estrategias de desarrollo en perspectiva comparada". En: Revista Vínculos, núm. 8.

Robbins, D. (1995). Trade, trade liberalization and inequality in Latin America and East Asia: Synthesis of seven country studies. Cambridge: Harvard University.

Sánchez, A. (2004). "Movilidad intergeneracional de ingresos y educativa en España 1980-1990". Documento de trabajo del Institut d'Economia de Barcelona, núm. 2004/1.

Torche, F. (2007). "Movilidad intergeneracional y cohesión social: Análisis comparado de Chile y México". Documento preparado para el Proyecto Nascal, Cieplan-iFHC, octubre de 2007.

- (s.a.). "Movilidad intergeneracional en México: Primeros resultados de la encuesta ESRU de Movilidad Social en México". Consultado por última vez el 15 de agosto de 2015 en:

http://www.ceey.org.mx/pdf/Movilidad\%20Social/MovilidadSocial_Torche_MovilidadMexico. pdf

Recibido: 29/09/15

Dictaminado: 12/04/16

Corregido: 12/04/16

Aceptado: 13/04/16 